\title{
Ephemeral Magma Chambers in Neoproterozoic Jiuling Composite Batholith in South China: batholith assembly by accretion of extremely diverse in $\delta^{18} \mathrm{O}$ zircons-saturated magma batches
}

DI WANG ${ }^{1}$, XIAO-LEI WANG ${ }^{1 *}$, ILYA N. BINDEMAN ${ }^{2}$, DE-HONG Du ${ }^{1}$, Jun-YONG LI $^{1}$, CHANG-HONG JiANG ${ }^{1}$

${ }^{1}$ State Key Laboratory for Mineral Deposits Research, School of Earth Sciences and Engineering, Nanjing University, Nanjing 210046, China

${ }^{2}$ Department of Earth Sciences, University of Oregon, Eugene, OR, USA

*correspondence: wxl@nju.edu.cn

Large volume magma bodies in the crust are crucial to magmatic differentiation and intracrustal mass redistribution. Its status in the upper crust, especially the magmatic residence timescale and magma flux, controls the intensity of magmatic activities and the formation of economic deposits. Here we explore the potential of using zircon crystal size distributions (CSD) and oxygen isotopic diffusion model to constrain magmatic timescale and magma flux of four main intrusions from the ca. 826 810 Ma Jiuling composite batholith in eastern Jiangnan Orogen, South China.

We present $\mathrm{U}-\mathrm{Pb}$ ages and co-registered $\mathrm{O}$ isotopes in zircons from four main intrusions from the batholith. Zircons have extremely high and variable $\delta^{18} \mathrm{O}$, which indicate derivation from diverse $\delta^{18} \mathrm{O}$ proto-sedimentary sources. Moreover, they yield remarkable oxygen isotopic heterogeneity (up to $8.1 \% \delta^{18} \mathrm{O}$ ), resulting from mixing and dissolution. Zircon CSD measurements reveal short zircon crystallization timescales and thus magmatic residence on the order of $10^{3}$ to $10^{4} \mathrm{yr}$, which is proven by the maximum residence (18-42 kyr, as an upper limit) constrained by zircon oxygen isotopic diffusion modelling. Among them, three intrusions (i.e. Meiling, Jiuling and Shihuajian) yield maximum magma fluxes of $4.75 \times 10^{-2} \sim 3.77 \times 10^{0} \mathrm{~km}^{3} / \mathrm{yr}$, higher than the critical flux, to possibly maintain large magma chambers. In contrast, the Jiuxiantang intrusion yield a maximum magma flux of $3.99 \times 10^{-3} \mathrm{~km}^{3} / \mathrm{yr}$. A compilation of the magma flux from worldwide upper-crustal intrusions suggests no large magma chamber could be a universal characteristic for intrusions in the upper crust. 